\title{
A solidão dos mineiros: mineiridade, patrimônio cultural e os processos de hierarquização de pessoas e lugares em Minas Gerais ao longo do século XX
}

\author{
The "mineiros" loneless: "mineiridade", cultural heritage and the hierarchical \\ processes of people anda places in Minas Gerais throughout the 20th century
}

Carolina Paulino Alcântara ${ }^{1}$

\begin{abstract}
Resumo
Analisar o conjunto de representações construído sobre Minas Gerais, ao longo do século XX, implica (re) pensar a forma como a constituição da mineiridade e do patrimônio cultural revela processos de classificações e hierarquizações de pessoas e lugares. Isso porque a existência de dois pólos opostos que se destacaram na formação histórica de Minas Gerais, e o conjunto de elementos representativos associados a eles, trazem à tona contrastes, esquecimentos e desigualdades... revelando o que conceitualmente vamos identificar como solidão. Ao longo da história de Minas Gerais, a região das Minas representou a sociedade que se formou nos núcleos urbanos em prol da mineração, estando sua população constantemente associada ao que se entendia por civilização, e os Gerais aludem às populações organizadas a partir da criação de pecuária nos sertões, principalmente na porção norte do estado. Os grupos dirigentes recorrentemente associaram estes espaços e sua gente ao que entendiam por atraso, tradição e ao jeito de viver refratários à mudança. Sendo assim, este artigo procura trazer algumas inquietações que objetivam problematizar as representações homogeneizantes construídas para falar sobre Minas Gerais. Buscarei a historicidade no campo das práticas e discursos em torno da seleção de elementos de identidade, da cultura e da história.
\end{abstract}

Palavras-chave: mineiridade; patrimônio cultural; representação; memória; solidão.

\begin{abstract}
Analysing the set of representations built about Minas Gerais, throughout the 20th century, implies (re) thinking how the constitution of "mineiridade" and Cultural Heritage reveals processes of classifications and hierarchies of people and places. That's why the existence of two opposite poles that stood out in the historical formation of Minas Gerais, and the set of representative elements associated with them, brings up contrasts, forgetfulness and inequality... revealing what we are conceptually identifying as loneliness. Throughout the history of Minas Gerais, the Minas region represented the society that formed in urban centers in favor of mining, with its population constantly associated with what was meant by civilization, and the Gerais alluded to the populations organized from the creation of livestock in the hinterlands, mainly in the northern portion of the state. The governing groups repeatedly associated these spaces and their people with what was understood by delay, tradition, and the way of living refractory to change. Thus, this article seeks to bring up some concerns that aim to problematize the homogenizing representations built to talk about Minas Gerais. We will look for

\footnotetext{
${ }^{1}$ Possui graduação em História (bacharelado e licenciatura) pela Pontifícia Universidade Católica de Minas Gerais (2012), mestrado e doutorado em andamento em História pela Universidade Federal de Minas Gerais (2015). E -mail: carolinapalcantara@ hotmail.com.
}

Recebido em 20 de julho de 2020. Aprovado em 16 de setembro de 2020. 
historicity in the field of practices and discourses around the selection of elements of identity, culture, and history.

Keywords: "mineiridade"; Cultural Heritage, representation; memory; loneliness.

\section{Introdução}

\section{O nó da nossa solidão... reflexões sobre o objeto de pesquisa a partir das aflições do tempo presente}

Neste texto, apresentarei algumas questões ainda incipientes relativas aos estudos do meu projeto de doutorado que dizem respeito aos elementos de identidade mobilizados por lideranças mineiras para representar as pessoas e os lugares na história de Minas Gerais. Pretendo tratar das recordações e das produções de esquecimentos nas construções das narrativas históricas sobre o estado, levando em consideração os contextos, os conflitos nos usos do passado e os debates em torno da seleção do patrimônio cultural estadual, objeto de estudo da minha pesquisa.

Para o desenvolvimento desta temática, torna-se imprescindível pensar a questão da memória a partir de um olhar sensível voltado para os processos que envolvem lembrar e esquecer. Paralelamente, será necessário entrar em contato com questões e sentimentos profundos que evidenciam traumas e a nossa relação com o mundo em que vivemos, desde as experiências de nossos antepassados, perpassando pelas nossas próprias vivências até, intrinsecamente ao coletivo, constituir em uma memória social.

Olhando para este processo de preencher e criar vazios, que constitui a reconstrução do passado por meio da memória ${ }^{2}$, os sentimentos de ausência e de solidão talvez sejam as maiores angústias compartilhadas por mulheres e homens da América Latina, que lidam cotidianamente com as cicatrizes de diferentes mutilações sofridas, entre elas de um passado de negativas, incluindo a ausência de representações em uma narrativa histórica. Isso porque a trama da constituição da memória e das identidades envolveu práticas de seleção e exclusão de pessoas e lugares, desde os primeiros conflitos oriundos da presença dos colonizadores europeus no nosso continente. Ela se aprofundou com os processos de apagamento de trajetórias de inúmeras famílias desterritorializadas da África e submetidas à escravidão.

Sobre este processo histórico marcado por ausências e solidão, Gabriel García Márquez (1969), em Cem anos de Solidão, denunciou a condenação das estirpes latino-

\footnotetext{
${ }^{2}$ Conferir MITRE, 2003, p.11-28.
} 
americanas a um século de solidão ao contar sobre a trajetória da família Buendía em uma fictícia cidade chamada Macondo. Ao longo da narrativa, a população local vivenciou diferentes conflitos, insurreições, imposições por parte de um governo central, processos de modernização, entre outras etapas do desenvolvimento local que facilmente identificamos como pertencentes a nossa própria história. A cada nova página, fica evidente a preocupação de Garcia Márquez por dizer da importância da coletividade, das tradições e da solidariedade visando criar um mundo de possibilidades frente ao direito à felicidade e à liberdade, que em muitos casos nos foi negligenciado.

Quando ganhou o Prêmio Nobel, o autor retomou suas análises históricas sobre as representações construídas sobre o continente afirmando que não tivemos um instante sequer de sossego, desde a chegada, a conquista e a violência dos primeiros europeus (GARCIA MÁRQUEZ, 2014). ${ }^{3}$ Segundo o escritor, a colonização europeia sobre a América negou a humanidade, a cosmovisão, os modos de viver e reforçou a lógica de exploração e submissão, que se intensificou com a consolidação do mundo burguês capitalista. Na leitura de Garcia Marquéz, as mulheres e os homens latino-americanos lutaram e resistiram também às guerras, aos golpes de Estado, às interrupções democráticas e a um conjunto de fatores socioeconômicos que condenou (e ainda condena) famílias inteiras a uma vida de ausências.

Sem a efetiva conquista dos direitos à vida, à saúde, à educação, à participação democrática e, enfim, à dignidade humana, as populações periféricas do continente continuam a sofrer com essas negativas e vivenciam, dia após dia, as mortes cotidianas, tendo, em muitos casos, o próprio Estado como um dos principais operadores do desaparecimento dos mais vulneráveis. Para Garcia Márquez, estas marcas constituem o nó da solidão... uma vida marcada pelas desigualdades de condições e a insuficiência de recursos básicos para a manutenção do essencial.

Olhando especialmente para o caso brasileiro, que recebeu o maior número de pessoas traficadas da África, os estudiosos e a população em geral percebem que o sistema escravista deixou sequelas tão profundas, que a nossa sociedade lida cotidianamente com suas mazelas que ainda machucam e matam a partir da violência policial, da negligência

\footnotetext{
${ }^{3}$ Discurso pronunciado na cerimônia de entrega do Prêmio Nobel de Literatura de 1982. Em 2014, em decorrência da morte do autor, a revista RevIU resolveu homenageá-lo publicando o original em espanhol e sua tradução para o português.
} 
estatal e de todo um projeto de sociedade baseada na estrutura das concepções raciais. ${ }^{4}$ Nesse sentido, historicamente, a solidão do povo brasileiro faz parte de um projeto político de aniquilação das identidades e da despolitização por meio do desconhecimento da própria história. A luta de classes no Brasil tem como passado uma experiência escravocrata que criou barreiras quase intransponíveis para a conquista da cidadania. Diante da condenação do povo negro e dos pobres a uma vida de ausências, o racismo deve ser compreendido como elemento que agrava as condições de acesso aos meios de sobrevivência. ${ }^{5}$.

Por isso, considero que é este, enfim, o nó da solidão: uma vida marcada por negativas, pela construção da subalternização, da invisibilidade, da desvalorização, das desigualdades de condições e da insuficiência de recursos básicos para a manutenção do essencial, como bem alertou García Márquez ao refletir sobre a história da América Latina, há algumas décadas.

Diante de tudo isso, a escolha da minha temática de estudo e a sua relação com o conceito de solidão se justifica porque, em diferentes momentos da história de Minas Gerais, a seleção e a exclusão de elementos da cultura local para a produção de identidades ocorreu a partir do silenciamento. Isto é, pessoas foram caladas, desconsideram suas visões de mundo e, em muitos casos, foram representadas de forma abstrata e a-histórica. ${ }^{6}$

${ }^{4}$ Compreendo que é impossível falar da história do nosso país sem mencionar o conceito de raça e racismo, pois o racismo constitui como elemento estrutural, isto é, integra a organização econômica e política da nossa sociedade. Neste caso, falar da solidão da América Latina implica compreender que esta condição atinge principalmente a população negra (ALMEIDA, 2019). Vale refletir também sobre como o conceito de raça e etnia se reconfiguraram ao longo da história instituindo-se como categorias que visam classificar pessoas e lugares. Para isso, indico a leitura do livro do Antônio Bispo do Santos, Colonização, Quilombos: modos e significados (2015). Neste texto, Antônio Bispo analisa a questão sócio racial contemporânea e no início da colonização.

${ }^{5}$ Atualmente, a realidade descrita se aprofunda. As famílias brasileiras, principalmente as mais pobres, as indígenas e as afro descendentes, sentem-se cada vez mais solitárias frente ao medo e à angústia causada pelo avanço da pandemia do Coronavírus, descoberto em dezembro de 2019 na China As alternativas de distanciamento social recomendadas para conter a disseminação do vírus não se constituem como medidas aplicáveis à realidade de milhares de trabalhadoras (es), pois a maioria vive em aglomerados urbanos, utiliza meios de transportes públicos ineficientes e cheios, lida cotidianamente com situações precárias de trabalho e está passando por necessidades econômicas. Diante do quadro de incertezas e da falta de assistência devida, cabe a maioria dos brasileiros arriscar-se, porém lutando, para não ser engolida frente a mais um capítulo de negativas: o agravamento de uma crise econômica e sanitária, o número insuficiente de leitos disponíveis no sistema de saúde pública, a morte anunciada e/ou uma despedida solitária

${ }^{6}$ Os seres humanos detêm conceitos, preconceitos e noç̃oes que interferem na forma como veem culturas distintas das suas. Ao longo dos processos de colonização, esse olhar de uma cultura sobre a outra levou a métodos de dominações, violências e de sobreposições. O termo a-histórico aparece aqui em referência à forma como os europeus impuseram sua cultura caracterizando os povos originários da América e o povo afrodescendente a partir de imagens animalescas, infantilizadas e, enfim, sem história. Vale conferir o clássico texto do Tzvetan Todorov (2003). Também sugiro a leitura dos textos de Boaventura de Souza Santos (2009) e Ailton Krenak (2019) que discutem o pensamento colonial a partir da construção de bordas 
Este processo ocorreu a partir das noções que evidenciam olhares distintos para os lugares e as pessoas no território mineiro, ao longo da história de Minas Gerais. A divisão do estado entre as Minas e as Gerais instituiu dualidades opostas que designam identidades. Aos olhos dos colonizadores, a região das Minas representou a sociedade que se formou nos núcleos urbanos em prol da mineração, estando sua população constantemente associada ao que se entendia por civilização. Os Gerais, por sua vez, fazem alusão às populações organizadas a partir da criação de pecuária nos sertões, principalmente na porção norte do estado. Este espaço e sua população eram constantemente associados a partir do que os colonizadores entendiam por atraso, tradição e ao jeito de viver refratários à mudança.

Esta interpretação sobre a constituição de Minas Gerais (FARIA, 1992) leva em consideração, por sua vez, o pensamento social que toma os termos sertão e litoral para revelar os contrastes, esquecimentos e desigualdades na formação do Brasil. No período colonial, litoral delimitava o espaço conhecido e dominado pelo colonizador. Sertão era a sua antítese: oposto da civilização, local da barbárie, área vasta e ocupada pelo outro de cultura e modos de vida que muitas vezes ignoravam as leis e os costumes metropolitanos. Durante o século XIX, a dualidade sertão/litoral continuou a reforçar a posição de superioridade e de centralidade da sociedade litorânea, que marginalizava as regiões interioranas.

Com a instauração da República, em 1889, a noção de sertão se reconfigurou, passando a conformar também o que se entendia por identidade brasileira. ${ }^{7}$ Nesse sentido, o sertão paradoxalmente representava tanto o berço do que chamavam de legitimamente brasileiro como um empecilho que segurava o país como uma âncora na caminhada em busca pelo progresso. Com efeito, o sertão não estava mais associado apenas às regiões interioranas do país, mas abrangia todo local onde as ações do governo não chegavam. Portanto, vale dizer que o sertão e o litoral revelavam (e revelam) a constituição desigual e hierarquizada da nossa sociedade, havendo participação dessemelhante da população nas decisões políticas e no desenvolvimento econômico e social do país. No processo de conformação das desigualdades, coube ao sertão, e especificamente para o sertão mineiro, a ausência e a solidão.

hierarquicamente arranjadas desvalorizando e negando os conhecimentos e práticas dos povos do sul do globo. Eles propõem perspectivas decoloniais no sentido de reconfigurar a geopolítica dos saberes, trazendo o reconhecimento de outros conhecimentos e práticas.

${ }^{7}$ Sobre esse assunto ver o artigo de Janaína Amado (1995, p. 145-151); o texto de Candice Vidal e Souza (1997); e o livro da Nísia Verônica Trindade Lima (2013). 
Além de ter como referência as análises desenvolvidas até aqui, o meu tema de pesquisa passou a fazer sentido também a partir das inquietações pessoais, que me motivaram na delimitação do objeto.

Percorrendo por estradas de asfalto e terra em Minas Gerais, me deparei com muita gente em sua $\operatorname{terra}^{8} .$. local de muitas vivências, origens, paisagens, comidas, sotaques, histórias, tradições e tudo o que, a partir do jeito de viver, das relações com os familiares e dos costumes de sua comunidade, constituem os múltiplos aspectos associados à noção de identidade. Sendo assim, foi a partir das vivências que tive no nordeste mineiro, contando com experiências de trabalho na área do patrimônio cultural e outros estudos voltados para análises sobre o sertão mineiro, que surgiram alguns incômodos. Conversei com muitas pessoas que me mostraram o quão diferente é este território unido por um conjunto de representações específicas elaboradas e contadas para dizer sobre Minas Gerais.

Deste modo, diante de tudo o que foi exposto, este artigo procura evidenciar algumas dessas inquietações por meio de reflexões que objetivam problematizar as representações homogeneizantes construídas sobre a memória de Minas Gerais. Busco a historicidade no campo das práticas e dos discursos durante um longo processo marcado pela formação das identidades mineiras. Este caminho é marcado por luta entre forças que buscavam a afirmação das influências políticas e econômicas no estado, principalmente da região centro-sul, em detrimento dos sujeitos do norte e nordeste.

Acredito que trazer à tona as análises sobre a conformação das nossas identidades faz parte de um processo político para construção das liberdades e da autonomia de um povo. Somente seremos livres e autônomos para trilhar nossa própria travessia quando compreendermos a necessidade do autoconhecimento. Por isso, em prol de uma história regional e que contribua para uma melhor compreensão da realidade que nos toma hoje e ontem, alerto para o fato de que o não entendimento sobre nós mesmos e sobre a nossa história nos torna, nas palavras de Garcia Márquez, cada vez mais "desconhecidos, cada vez menos livres, cada vez mais solitários” (GARCIA MÁRQUEZ, 2014, p. 13).

\footnotetext{
8 Tendo como referência os sentidos atribuídos pelos moradores do Vale do Jequitinhonha para a palavra terra, a utilizo neste texto em alusão à ideia de localidade ou à morada de origem, conforme indica o dicionário do dialeto rural da região produzido por Carolina Antunes e Aderlande Pereira Ferraz (2013, p. 225). Sabe-se que é em sua terra que cada pessoa estabelece as relações cotidianas, que dão sentido para a sua existência. O dossiê de registro do artesanato em barro do Vale do Jequitinhonha traz essas reflexões sobre a relação das riquezas e vivências que vem da terra (IEPHA, 2018).
} 
Por isso, para que as palavras do autor de Cem anos de solidão não sejam condenadas ao esquecimento, cabe repeti-las: "Frente à opressão, ao saqueio e ao abandono, nossa resposta é a vida"! E em meio a um contexto que impõe, cada vez mais, mais variáveis de "solidões", desejo uma vida de autonomia, liberdade e felicidade: "onde ninguém possa decidir por outros até mesmo a forma de morrer onde verdade seja certo o amor e seja possível a felicidade e onde as estirpes condenadas a cem anos de solidão tenham finalmente e para sempre uma segunda oportunidade sobre a terra" (GARCIA MÁRQUEZ, 2014, p. 13-14).

Por fim, dedico estas páginas aos mineiros e às mineiras mortas pela Covid-19. Aos seus familiares, os meus mais sinceros sentimentos, sabendo que, por trás de números, existem vidas que se conectam, de alguma maneira, por meio das palavras que se seguem.

\section{Sobre as inquietações acerca de representações que silenciam e condenam muitos mineiros a solidão...}

Em diferentes momentos da história de Minas Gerais, os mineiros se identificaram e/ou mobilizaram um conjunto composto por elementos representativos que consideram essenciais para dizer de si mesmos. Estas representações compreendem, desde informações contempladas em aspectos geográficos e físicos da paisagem das diversas regiões que compõem o estado, passando pelas distintas edificações, em especial a colonial, chegando em questões que variam entre os modos de viver, celebrar, rezar e fabricar alimentos, por exemplo.

Essas noções que compõem o imaginário social ${ }^{9}$ recaem sobre valores, costumes e tradições presentes na memória afetiva e social de cada pessoa nascida e/ou radicada no estado. Em relação à história de Minas Gerais, percebo uma certa centralidade nos discursos representativos evocados, principalmente pelas elites da região centro sul do estado em detrimento do norte e nordeste. Nesse sentido, retomo as ideias iniciais: a solidão, enquanto conceito utilizado para falar de uma vida de negativas e ausências, também é compartilhada pelos mineiros. Pois, ao longo do tempo, a reconstrução sobre o passado fez-se a partir da apropriação e formas diferentes de ressignificar elementos da

\footnotetext{
${ }^{9}$ Utilizo o conceito proposto por Bronislaw Baczko (1985), em A imaginação social, que diz que o imaginário é algo próprio da vida social, determinando a formação de representações e identidades. Segundo o autor, toda sociedade elabora um conjunto de referências por meio do qual estabelece suas relações e é através de seu imaginário que a coletividade cria sua identidade, elabora certa representação de si, estabelece suas expectativas e aspirações, designa papéis e posições sociais, bem como cria e impõe crenças e regras.
} 
identidade local, incorporando outros referenciais e criando imagens sobre as pessoas e locais do estado. Os esquecimentos e silenciamentos marcaram este processo que, em muitos momentos, desconsideraram diferentes grupos sociais na formação identitária.

É preciso considerar que Minas Gerais corresponde em sua extensão territorial a muitos países do globo. Entretanto, apesar das múltiplas experiências, vivências, tradições, sotaques, modos de fabricar alimentos etc., é unido por um conjunto de representações específicas elaboradas e divulgadas por diferentes sujeitos ao longo do tempo. O caso do Norte e Nordeste de Minas Gerais é bem emblemático nesse processo, porque ao mesmo tempo que foram incluídos com valor negativo na identidade mineira, foram dela excluídos. ${ }^{10}$ Desse modo, a reprodução e permanência de elementos centralizados em uma cultura local específica, caso da região centro-sul, pode ser percebida na fala das lideranças artísticas, políticas, intelectuais e de pessoas comuns.

Guimarães Rosa, por exemplo, em texto publicado na revista $O$ Cruzeiro, em 25 de agosto de 1957, destaca que "Minas Gerais é muitas. São, pelo menos, várias Minas", mas que existe uma que é bastante divulgada e a que mais se refere: "Minas antiga, colonial, das comarcas mineradoras, toda a extensão da chamada Zona Mineralógica”. Segundo o escritor, trata-se da "Minas geratriz, a do ouro, que evoca e informa, e que lhe tinge o nome" (O Cruzeiro, em 25 de agosto de 1957).

Utilizando dessa mesma concepção de que a região da exploração do ouro representa o embrião na formação do estado, no campo da política, governantes de diferentes épocas tentaram manipular o imaginário acerca do "ser mineiro" visando construir uma narrativa de identificação com seus eleitores e, mais do que isso, legitimar o domínio de uma certa elite. Nesse processo, revelaram uma estratégia para garantir interesses regionais. Dessa forma, a Minas geratriz, mencionada por Guimarães, ora ou outra foi evocada por políticos buscando garantir a supremacia das regiões centro-sul, tradicionalmente ligadas ao centro político e econômico do estado, em detrimento de outras. Um dos casos mais recentes é a fala do político Aécio Neves em Comemoração do Dia de Minas, em Mariana, 16 de julho de 2001. Ele evoca as cidades construídas durante o ciclo do ouro para dizer sobre a origem histórica de Minas Gerais e, dentre elas,

10 Atualmente, o Movimento Catrumano, criado em 2005, consiste em uma reação ao esquecimento de pessoas e lugares para representar Minas Gerais. Como resultado, foi instituído o "Dia dos Gerais" com o objetivo de fazer um resgate histórico do Norte de Minas a partir do reconhecimento da cidade de Matias Cardoso como o primeiro núcleo de povoação do estado. O processo de ressignificar o papel desempenhado por esta porção do estado na consolidação e fundação de Minas Gerais é um desdobramento da tese de doutoramento de João Batista de Almeida Costa (2003). 
destaca a importância de Mariana como local onde "se fundam os alicerces cívicos de nossa gente" (Aécio Neves apud ÂNGELO, 2005, p. 108).

Diante do conjunto de elementos simbólicos escolhido por diferentes segmentos da sociedade mineira, em épocas distintas para representar este território e sua gente, passei a me questionar em que medida a nomeação de bens culturais e históricos a partir de concepções, projetos, interesses e demandas dos grupos dirigentes do estado acompanharam e/ou determinaram esses referenciais na construção do imaginário sobre Minas Gerais. Estou falando das disputas por memória na formação da identidade mineira a partir da análise história sobre as ações governamentais para o patrimônio cultural, ao longo de todo o século XX.

Para as análises deste texto, levarei em consideração, inicialmente, as atividades implementadas pelo governo do estado para a seleção do patrimônio cultural mineiro, em 1926, por meio da criação da Inspetoria Estadual de Monumentos. Posteriormente, vou mencionar a atuação das instituições voltadas para a cultura, desenvolvimento social e para patrimônio, durante as décadas de 1960, 1970 e 1980, como o Instituto Estadual do Patrimônio Histórico e Artístico de Minas Gerais (IEPHA-MG) e a Fundação João Pinheiro. Em seguida, citarei a Lei nº12.040, ou Lei Robin Hood, de 1995, que descentralizou a distribuição da cota-parte do imposto sobre circulação de mercadorias e prestação de serviços de transporte interestadual e intermunicipal e comunicação (ICMS) dos municípios mineiros de modo a desconcentrar renda e distribuir recursos para regiões mais pobres. A aplicação dos recursos municipais nas áreas sociais representou um importante passo para a destinação de verba para o patrimônio cultural, que seria consolidada posteriormente com a Lei ${ }^{\circ} 18.030$ de 2009, que incluiu diferente critérios para distribuição da cota-parte do ICMS, como o patrimônio cultural. ${ }^{11} \mathrm{Na}$ década de 1990, após significativos avanços na área de proteção de bens culturais, principalmente com a Constituição de 1988 e a Constituição do Estado de Minas Gerais de 1989, assistimos a um processo de descentralização das ações oriundas do governo do estado para garantir o reconhecimento, registro e tombamento. Este processo também foi marcado por desmantelamento e, ao mesmo tempo, evidencia tensões, conflitos e preconceitos, da qual tratarei mais à frente para justificar as inquietações apresentadas no início do texto.

\footnotetext{
${ }^{11}$ Disponível em: $\quad$ htps://www.almg.gov.br/consulte/legislacao/completa/completa-nova-

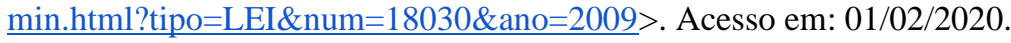


Diante de tudo isso, entendo que as políticas públicas voltadas para o patrimônio cultural em Minas Gerais estiveram, por muito tempo, centralizadas em ações promovidas diretamente pelo Governo do Estado, que atuou em busca de elementos simbolicamente representativos na tarefa de "inventar" Minas Gerais. Ou seja, as sucessivas (re)interpretações sobre o estado, desenvolvidas neste contexto por meio de políticas públicas, evidenciam uma constante procura por narrativas históricas que abordam aspectos da identidade e representatividade sobre a região e sua gente.

A escolha por um ou outro elemento histórico, social e/ou cultural para representar os mineiros dependeu, por sua vez, das forças políticas e econômicas, já que inúmeros discursos com caráter centralistas foram anunciados principalmente por lideranças da região centro-sul do estado com o objetivo de evocar uma identidade mineira, excluindo outras porções do estado. Deste modo, a reprodução e permanência de elementos centralizados em uma cultura local específica pode ser percebida na fala das lideranças artísticas, políticas e em fala de pessoas comuns.

Sendo assim, existe a necessidade de refletir sobre a construção de um conjunto de representações sobre Minas Gerais a partir das considerações possíveis acerca da noção de patrimônio cultural e da mineiridade. Nesse sentido, compreendo que os dois conceitos se referem a todo um sistema de representações simbólicas.

O patrimônio cultural envolve as construções sociais, que são frutos de escolhas, depende da atuação de grupos políticos e, portanto, vem das relações de conflitos que envolvem memória e poder (CHAGAS, 2009, p. 136-171). No mundo ocidental, as concepções acerca do patrimônio ${ }^{12}$, atrelada aos elementos de representatividade e identidade, como a riqueza moral e material pertencentes a um conjunto de cidadãos, formaram-se no contexto da instituição dos Estado-Nação, mais precisamente, pósRevolução Francesa. Isso ocorreu quando se desejava fazer com que a população se reconhecesse sob um novo formato de Estado a partir da acumulação de diversidade de objetos que se congregam por seu passado comum (CHOAY, 2001, p. 95-125).

Principalmente a partir do século XIX, com a consolidação da sociedade capitalista industrial, que fincou suas bases com as revoluções burguesas e industrial, a palavra patrimônio assumiu contornos semânticos específicos associados às

\footnotetext{
${ }^{12}$ Saindo do âmbito do privado, enquanto herança familiar transmitida, a palavra patrimônio foi requalificada ao longo da história a partir de diversos adjetivos, como natural, histórico, cultural etc. Essas noções esclarecem as relações das sociedades ocidentais com a temporalidade e por meio da qual construíram suas identidades (CHOAY, 2001).
} 
representações materiais de uma "identidade" e de uma "memória", atrelados ao universo mental e social de uma cultura, determinando uma autoconsciência cultural e como bem coletivo (GONÇALVES, 2009, p. 25 - 33).

Entretanto, foi no contexto do pós-Guerras Mundiais, diante das violências cometidas contra as populações civis de diferentes nações participantes dos conflitos, que se delineou uma noção de patrimônio associada à concepção revisada de cultura. A partir disso, configurou-se a ideia de um patrimônio cultural a ser preservado que incluísse o conjunto de realizações humanas em suas mais diversas expressões. Essa noção incorporava tanto um acervo de realizações materiais como imateriais da vida em sociedade. No Brasil, esta discussão em torno do patrimônio ganhou força durante o governo de Getúlio Vargas, que se empenhou na busca pela construção de uma “identidade nacional”, durante a década de 1930.

Minas Gerais acompanhou a movimentação nacional, entretanto a mineiridade enquanto imaginário regional, que se disseminou dentro e fora do estado a partir de diferentes elementos de identificação e representação, antecede essa discussão a partir de diferentes escritores que buscaram (re)escrever a história do estado com o advento da República. Falarei sobre isso mais a frente.

De todo modo, na relação entre a mineiridade e o patrimônio cultural, percebo que a construção da ideia do "ser mineiro", esteve, em muitos casos, atrelada às escolhas efetuadas por órgãos investigativos e de preservação da história de Minas Gerais revelando a seleção e a exclusão de elementos representativos, bem como de regiões e pessoas, em todo o contexto mencionado.

É sobre esse processo de produção de escolhas e esquecimentos, revelando hierarquias entre pessoas e lugares, que estou chamando por solidão dos mineiros. A dor do esquecimento e da invisibilidade das especificidades culturais e identitárias conforme denunciou João Batista de Almeida Costa (2003), que escreveu sobre a aflição que os mineiros do Norte sentem diante da ambiguidade do lugar ocupado por eles no conjunto de Minas Gerais. Algo semelhante passa com as comunidades do Vale do Jequitinhonha, que lidam historicamente com todo universo de imagens negativas sobre sua terra, o que colaborou para a construção de estereótipos, como o Vale de Miséria e da seca, na década de $1970 .{ }^{13}$ Para ter uma ideia, na cultura artesanal local, é recorrente a produção de peças

\footnotetext{
${ }^{13} \mathrm{O}$ Vale do Jequitinhonha foi incluído como uma das regiões para fins de planejamento de Minas Gerais, em 1973, em decorrência de um estudo de regionalização, produzido pela Fundação João Pinheiro. Conferir o texto de Matheus de Moraes Servilha (2012) sobre a formação da região.
} 
em cerâmica que trazem "a ideia do sofrimento, seja pelas populações nativas colonizadas e resistentes ao processo de submissão, ou pelas pessoas negras escravizadas no passado" (IEPHA/MG, 2018, p. 51). As artesãs não deixam de dizer também sobre o histórico de carências nos investimentos do setor público.

\section{Evocando a "Minas Geratriz": as elites da região centro-sul no processo de consolidação política e econômica no estado e sua relação com conformação da mineiridade e o patrimônio cultural}

A abordagem historiográfica sobre as diferentes interpretações e olhares para a história, as paisagens e a população mineira é abrangente, envolvendo pesquisadores atentos aos diferentes retratos produzidos sobre Minas Gerais. ${ }^{14}$ Entre esses estudos, é dada especial atenção aos discursos apregoados por políticos e intelectuais, que iniciaram, com o advento da República, projetos apoiados na construção de uma identidade mineira. ${ }^{15}$

Nesse sentido, muitos autores destacam que a proclamação da República levou a um movimento de ressignificação de olhares e interpretações sobre o território mineiro, uma vez que colocou em evidência, a partir do movimento político federalista no Brasil, as particularidades regionais que as elites políticas e econômicas desejavam associar a sua história e cultura (CARVALHO, 2010). Essas diferentes narrativas eram estabelecidas principalmente a partir dos discursos das lideranças das regiões centro e sul que desejavam garantir a centralidade na tomada de decisão, justificando uma suposta necessidade de coesão interna para fortalecimento do estado no cenário nacional e, consequentemente, garantir o repasse de recursos. ${ }^{16}$

A criação de instituições voltadas para a memória e pesquisa, como o Arquivo Público Mineiro (APM) ${ }^{17}$, em 1895, e o Instituto Histórico e Geográfico de Minas Gerais

\footnotetext{
${ }^{14}$ Muitos estudiosos debruçaram sobre o tema da construção de Minas Gerais a partir de diferentes referenciais. Ver os autores: Jean Luiz Neves Abreu (2005); Ângelo Alves Carrara (1999); Cid Rabelo Horta (1986); Letícia Julião (1992); João Antônio de Paula (2000); Liana Maria Reis (2007); Luiz Carlos Villalta (2007a); Luiz Carlos Villalta (2007b); entre outros.

${ }^{15} \mathrm{~A}$ mineiridade como um tema para análise histórica dos processos que envolvem a experiência republicana pode ser identificada em vários estudos como, por exemplo: José Murilo de Carvalho (2005, p. 55-78); Maria Auxiliadora Faria (1992); Walderez Simões Costa Ramalho (2015); entre outros.

${ }^{16}$ A construção de Belo Horizonte e o discurso da mineiridade são exemplos dessas ações e discursos das elites da região centro-sul do estado que desejavam promover a convergência e a unidade de Minas Gerais, excluindo a porção norte do debate. Sobre a formação do norte mineiro e os conflitos políticos e econômicos envolvidos neste processo ver o livro de José Moreira de Souza (1993).

17 A criação do Arquivo Público Mineiro, em 1895, teve papel fundamental no início da construção da narrativa histórica sobre Minas Gerais no período republicano, podendo ser considerada a mais antiga instituição cultural do estado. "Como percebemos, o APM proporcionou ao projeto político de reconstituição histórica de Minas Gerais um local de produção de conhecimento a respeito desse passado,
} 
(IHMG) ${ }^{18}$, em 1907, está inserida neste mesmo processo de escrita de uma "nova" história de Minas Gerais a partir da seleção de acontecimentos e personagens de um passado tido como "comum" aos mineiros. Ambas objetivavam estabelecer uma nova etapa para o momento político e constituir os fundamentos para a caracterização da história local (RAMALHO, 2015).

Apesar da República ter inaugurado um novo regime de historicidade ${ }^{19}$ baseado na busca pelas singularidades regionais, foi quase na virada para os anos 1930 que deu início a ações estatais mais efetivas no que diz respeito à produção/construção do patrimônio cultural com a criação, por exemplo, em 1926, da Inspetoria Estadual de Monumentos em Minas Gerais.

Desde meados da década de 1920 já se assistia uma movimentação por parte de lideranças políticas no sentido de garantir certo "cuidado" com o consideravam como patrimônio mineiro. Em 1924, o deputado natural de Minas Gerais, Augusto de Lima, apresentou à Câmara o Projeto de Lei nº181, que proibia a saída de obras de artes brasileiras. Um ano depois, Jair Lins, jurista mineiro, elaborou um anteprojeto muito semelhante ao de Lima. Neste mesmo ano, em 4 de junho de 1925, Fernando de Mello Vianna, presidente de Minas Gerais, organizou uma comissão para que elaborasse um projeto para impedir a "dilapidação do patrimônio das velhas cidades mineiras" (RANGEL, 2010, p. 119-135).

A instauração de uma Inspetoria Estadual de Monumentos em Minas antecipou um movimento que seria inaugurado, em nível nacional, somente oito anos depois, com

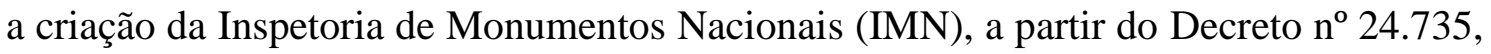
de 14 de julho de 1934. Assistia-se, nesse momento, a uma preocupação por elencar objetos e edificações representativos da identidade nacional, uma vez que a Constituição Federal de 1934 previa a responsabilidade do governo federal, estadual e municipal em proteger os objetos de interesse histórico e pertencentes ao patrimônio artístico (BRASIL, [2019a]). Nesse sentido, cabia a IMN promover um levantamento, a título de sugestão ao

bem como um lugar simbólico que resguardava uma unidade territorial ainda carente de delimitações precisas" (ARAÚJO, 2007, p. 31).

${ }^{18}$ O Instituto Histórico e Geográfico de Minas Gerais surgiu em Belo Horizonte em 1907, a exemplo do Instituto Histórico e Geográfico Brasileiro (IHGB), fundado no Rio de Janeiro em 1838. O projeto do IHGB era de promover uma história da pátria e, com isso, fundar a ideia de uma nação brasileira. Isso refletiu o temor de uma possível fragmentação nacional, que as disputas políticas presentes nos momentos após a abdicação e Regência trouxeram. Conferir a dissertação de Loyane Aline Pessato Ferreira (2010) e o livro de José Carlos Reis (2007, p. 23-51).

${ }^{19}$ Novo momento histórico. Conferir HARTOG, 2006 
governo federal, daquilo que possivelmente seria dotado de um valor e interesse artísticohistórico existentes no país para que então se atribuísse o título de monumento. A IMN também ficaria encarregada de uniformizar a legislação sobre a proteção e conservação dos Monumentos Nacionais, bem como garantir a guarda e a fiscalização dos objetos histórico-artísticos, ao orientar os governos dos estados sobre o tema. Portanto, cada estado se responsabilizaria pelos encargos dessa atividade em seus territórios (MAGALHÃES, 2019).

Buscando ampliar as iniciativas voltadas para a legalização, institucionalização e sistematização da presença do Estado na vida política e cultural do país a partir da organização e proteção do patrimônio histórico e artístico nacional, o Decreto-lei $\mathrm{n}^{\mathrm{o}} 25$ de 30 de novembro de 1937 instituiu a criação do Serviço de Patrimônio Histórico e Artístico Nacional (SPHAN) ${ }^{20}$, definindo suas ações a partir da concepção de que o patrimônio histórico e artístico nacional era constituído pelo "conjunto de bens móveis e imóveis existentes no país e cuja conservação seja do interesse público quer por sua vinculação a fatos memoráveis da História do Brasil, quer por seu excepcional valor arqueológico ou etnográfico, bibliográfico ou artístico" (BRASIL, [2019c]). ${ }^{21}$ Baseado nas noções de "tradição" e de "civilização", os bens culturais classificados como patrimônio "deveriam fazer a mediação entre os heróis nacionais, os personagens históricos, os brasileiros de ontem e os de hoje". Compreende-se que "essa apropriação do passado era concebida como um instrumento para educar a população a respeito da unidade e permanência da nação" (CPDOC-FGV, 2019).

A partir de então, houve uma predominância, até o final do século XX, de um tipo de "atuação preservacionista, voltada prioritariamente para o tombamento dos chamados bens de pedra e cal - igrejas, fortes, pontes, chafarizes, prédios, conjuntos urbanos representativos de estilos arquitetônicos específicos" (ABREU, 2009. p. 13). Foi sob essa orientação que, em 1938, a cidade de Ouro Preto teve o seu centro histórico tombado, iniciando um projeto de reconhecimento e valorização dos elementos constitutivos da história e, consequentemente, da identidade brasileira e mineira.

A valorização deste patrimônio histórico a partir de ações do governo federal revelava também o olhar atento das elites mineiras para a preservação do passado e memória de Minas Gerais tendo como referencial a formação do estado a partir das

\footnotetext{
${ }^{20} \mathrm{~A}$ instituição veio a ser posteriormente Departamento, Instituto, Secretaria e, de novo, Instituto do Patrimônio Histórico e Artístico Nacional (IPHAN), como se chama atualmente (CPDOC-FGV, 2019).

${ }^{21}$ Art. $1^{\circ}$ do Decreto-lei no 25 de 30 de novembro de 1937 (BRASIL, [2019b]).
} 
atividades da mineração. Predominou, portanto, por parte do século XX, os discursos e ações das elites políticas e econômicas das regiões Centro, Sul e Zona da Mata do estado, que buscavam promover suas regiões e excluindo o Norte do estado do debate. As lideranças desses locais mantiveram certa consciência da centralidade, deixando em evidência no imaginário local a construção histórica do estado a partir de dois polos opostos: a região das Minas - em referência à sociedade que se formou nos núcleos urbanos em torno da mineração - e os Gerais - que fazia alusão à sociedade organizada a partir da criação da pecuária nos sertões, principalmente na porção norte do estado, que era constantemente associada ao atraso.

Algumas tentativas surgiram por parte do governo do estado para incorporar o sertão mineiro aos seus projetos de desenvolvimento político e econômico, o que refletiu em seu olhar para a cultura popular. Em 1964, por exemplo, instituiu-se a Comissão de Desenvolvimento do Vale do Jequitinhonha (Codevale) (MINAS GERAIS, 1971) "como autarquia de âmbito estadual, inspirada na Superintendência de Desenvolvimento do Nordeste (Sudene), agência do governo federal que buscava solucionar os problemas socioeconômicos da região" (VIEIRA, 2010, p. 170). Desse modo, o Vale do Jequitinhonha foi instituído como região geográfica para atuação do governo no enfrentamento dos baixos indicadores socioeconômicos, que associavam a região ao subdesenvolvimento. Em 1973, um estudo de regionalização, produzido pela Fundação João Pinheiro, instituída em 1969, definitivamente colocou o Vale como uma das regiões para fins de planejamento de Minas Gerais (SERVILHA, 2012, p. 38). O Vale do Jequitinhonha - ligado ao atraso, inserido, em parte, no semiárido nordestino brasileiro e recebendo a valoração de sertão - se configurava a partir da identidade de "Vale de Miséria" (RAMALHO, 2010, p. 34; MARTINS, 2012, p. 148-149). ${ }^{22}$

A década de 1970 ficou marcada por políticas públicas voltadas para a promoção do desenvolvimento econômico e social dessa região, procurando fazer do artesanato local uma ferramenta para melhorar a qualidade de vida das pessoas. Foi a forma como atuou a Secretaria de Estado do Trabalho, Ação Social e Desportos de Minas Gerais (SETAS) que seguiam as orientações do Programa Nacional de Desenvolvimento do Artesanato (PNDA). O programa visava criar condições de desenvolvimento e auto

\footnotetext{
${ }^{22}$ Em reação a esses estereótipos, estudantes oriundos do Vale fundaram o jornal Jornal Geraes, em março de 1978 e publicado até julho de 1985. Foi um veículo de comunicação que assumiu o papel de denúncia da realidade socioeconômica da região do Vale. Uma edição especial com todos os fascículos foi publicada em 2011 pelos fundadores (ABNER; MARTINS; SILBY. 2011).
} 
sustentação para os artesãos, colaborando, por sua vez, com a "preservação do artesanato em suas formas de expressão da cultura popular" (BRASIL, 1977).

Os estudos promovidos pela Fundação João Pinheiro a partir da produção de estatísticas e na criação de indicadores econômicos, financeiros, demográficos e sociais colaboraram com a atuação da Codevale, que vislumbrava aproveitar os recursos da região para o desenvolvimento local, caso do artesanato. Em 1979, a Fundação João Pinheiro, publicou o Mapeamento do Artesanato Mineiro, que identificava o artesanato como manifestação da cultura local e oportunidade de trabalho.

Preciso considerar que os esforços públicos destinados ao desenvolvimento do artesanato no Vale do Jequitinhonha evidenciam uma opção pelo popular a fim de preservar a cultura local como um legado da miscigenação entre a população indígena e portuguesa. Entretanto não se atribui a mesma valorização estética e histórica como foi dada às produções luso-brasileiras, que marcava a paisagem das cidades tidas como históricas em Minas Gerais. Nesse sentido, a Fundação João Pinheiro atuou diretamente como colaboradora das instituições de patrimônio, uma vez que parte do seu acervo institucional é composto por estudos realizados em cooperação com o IPHAN e com o Instituto Estadual do Patrimônio Histórico Artístico de Minas Gerais (IEPHA/MG) para a preservação dos bens de valores históricos e artísticos, como os de Ouro Preto e Mariana, por exemplo (FJP, 1973a; 1973b; 1975).

A criação do IEPHA, em 1971, serviu para viabilizar a proteção do patrimônio cultural, através de instrumentos de reconhecimento institucional (MINAS GERAIS [2019b]). Recentemente, a instituição publicou um Guia de bens Tombados (IEPHA/MG, 2014) contendo informações históricas e arquitetônicas sobre bens tombados pelo Estado. De acordo com o que foi observado até o momento para escrita deste texto, a trajetória da instituição explicita o movimento político de atuação destinada para o tombamento e restauro de igrejas, capelas, conjuntos arquitetônicos e centros históricos das regiões que compreendem ao que identificamos como pertencentes à cultura e paisagem das Minas. Mas outros estudos consultados também apontam que, a partir da década de 1980, a instituição passou a ter foco para aspectos da cultura imaterial e para a região norte e nordeste de Minas Gerais (MORAES; SOUZA, 2013).

Sobre o olhar atento das instituições brasileiras para o patrimônio histórico e artístico de Ouro Preto e Mariana, vale explicar a partir da relação de dois mineiros na área: Rodrigo Melo Franco de Andrade, atuando no SPHAN entre 1936 a 1967, e Sylvio de Vasconcellos, atuando no $3^{\circ}$ distrito do SPHAN em Minas Gerais. 
Rodrigo Melo Franco de Andrade manteve inúmeras ações voltadas para o patrimônio mineiro, entre elas o tombamento, em 1938, de seis cidades coloniais mineiras em sua totalidade: Ouro Preto, Mariana, Diamantina, Serro, São João Del Rei e Tiradentes. O nome de Antônio Francisco Lisboa, o Aleijadinho, também ficou consagrado como importante escultor mineiro a partir da promoção de Andrade (BRAGA, 2010, p. 58-59). Para além das atividades voltadas para o tombamento, conservação e restauração dos bens de pedra e cal, Rodrigo Melo Franco de Andrade matinha relações com intelectuais brasileiros e estrangeiros, sendo responsável por uma rede de debates sobre arte, história e cultura.

Sylvio de Vasconcelos, nascido em uma família composta por políticos, intelectuais e historiadores mineiros, atuou no campo do patrimônio cultural brasileiro a partir de estudos sobre a arquitetura tradicional. Tornou-se um dos grandes nomes na consagração das identidades mineiras ao publicar o livro Mineiridade: Ensaio de Caracterização, em 1969.

Sobre o diretor geral do SPHAN e o chefe do $3^{\circ}$ distrito de Minas Gerais, Vanuza Moreira Braga (2010) destaca pontos em comum: descendência de famílias tradicionais de Ouro Preto, "cujas trajetórias estão ligadas à defesa e construção de uma memória sobre a cidade, seja produzindo obras de caráter historiográfico, memorialístico ou militando pela preservação e valorização da antiga Vila Rica". A partir da atuação de cada um, ambos adotaram como missão "salvar o barroco mineiro e consagrá-lo como a maior manifestação do gênio nacional". Direcionaram suas ações, principalmente, "no sentido de proteger e restabelecer a honra da "joia de Minas", Ouro Preto, continuando o trabalho de seus ascendentes" (BRAGA, 2010, p. 81).

$\mathrm{O}$ aprofundamento sobre atuação de nomes que divulgaram concepções e ideias sobre Minas Gerais e agiram nas instituições de preservação do patrimônio contribui para um maior entendimento das relações possíveis entre a elite política, intelectuais, a construção da mineiridade e a seleção do patrimônio cultural mineiro. Também revela a relação existente entre as políticas públicas no estado com as que ocorriam no país, principalmente porque, em nível nacional, a orientação para o tombamento de bens passava pela escolha efetuada por grupos dirigentes que desconsideravam a contribuição de diferentes setores da sociedade na memória histórica do Brasil. Bem da verdade, mais do que desconsiderar, trataram como algo menor, indigno para representar a nossa identidade. 
Paulo César Garcez (2016), ao fazer um balanço das políticas patrimoniais federais, revela que as ações governamentais para a memória nacional estão marcadas por uma herança autoritária e excludente das práticas de eleição patrimonial. Isso porque, segundo o autor, permaneceu "um padrão elitista" que refletiu nas escolhas, nas pessoas que conduziam os processos e, nesse sentido, revelam a "hierarquização e a subrepresentação dos grupos étnicos e das práticas religiosas". Ao mesmo tempo, revela a “canonização de uma certa noção de mestiçagem - dimensões essas que serviram simultaneamente à celebração e à opacidade de agentes formadores do Brasil" (MARINS, 2006, 11-12).

Segundo o autor, esse cenário permanece até o início do século XXI, ainda que a legislação e a instituição do patrimônio imaterial, durante a redemocratização, visassem garantir maiores representatividades. A Constituição Federal de 1988 procurou garantir uma nova agenda patrimonial, que reconheceu o patrimônio imaterial como categoria passível de registro a fim de reconhecer e preservar os bens "portadores de referência à identidade, à ação, à memória dos diferentes grupos formadores da sociedade brasileira" (Artigo 216. BRASIL [2019b]).

Em nível local, a Constituição do Estado de Minas Gerais, promulgada em 1989, reafirmou a função do estado em legislar sobre a proteção do patrimônio e reiterou a função municipal de proteger o patrimônio entendido pela constituinte como "cultural e histórico", definindo o "patrimônio cultural mineiro" a partir de critérios tangíveis e intangíveis, históricos, artísticos, paisagísticos e científicos (MINAS GERAIS [2020]).

A partir de 1990, em decorrência de um processo de incentivo à atuação das prefeituras e empresas especializadas no trato com o patrimônio, a Lei no 12040 , de 28 de dezembro de 1995, dispõe sobre distribuição de parte da receita arrecadada com o Imposto sobre Operações Relativas à Circulação de Mercadorias e sobre Prestações de Serviços de Transporte Interestadual e Intermunicipal e de Comunicação -ICMS pertencente aos municípios (MINAS GERAIS [2019a]). Tendo as atividades culturais como um critério para repasse de verbas, a Lei 18030, promulgada em 2009, incentiva a execução de políticas de preservação do patrimônio cultural por parte das prefeituras, uma vez que colocava a ação como critério para o cálculo da parcela de repasse de parte do ICMS (MINAS GERAIS, 2009).

De fato, essa movimentação por parte do governo de Minas Gerais para ampliar as ações sobre o patrimônio tem a ver com um alargamento importante e perceptivo no reconhecimento e na representatividade dos grupos sociais constituintes da sociedade 
brasileira no que tange ao patrimônio cultural brasileiro a partir da década de 1980, conforme dito anteriormente. A seleção dos elementos identitários passou a contemplar edificações e vinculadas a diferentes grupos étnicos, como os imigrantes e os afrobrasileiros, e levou em consideração outras religiões para além da tradição católica, caso do candomblé que teve um primeiro terreiro tombado ainda nos anos 1980. Por essa época, também foram considerados estilos arquitetônicos que até então eram tidos como estranhos à tradição advinda do período colonial, tida até pouco tempo como efetivamente brasileira.

Entretanto, escrevendo sobre essas inovações no campo do patrimônio, resultantes de reivindicações e conquistas de grupos sociais historicamente marginalizados, é perceptível, nas análises contempladas pela literatura sobre o tema, que as disputas, no que diz respeito à memória e ao patrimônio, evidenciam, por outro lado e em larga medida, as reações conservadoras, principalmente em se tratando de uma sociedade socialmente desigual e formulada a partir da estrutura racial. Tomo como exemplo novamente a análise feita por Paulo César Garcez Marins (2006), que destaca contingenciamento do Estado para as políticas de preservação nos anos 1990, quase interrompendo o movimento iniciado na década de 1980. Com quase nenhuma renovação temática e metodológica, ainda manteve como referência para tombamento a paisagem luso-brasileira.

No que diz respeito às inovações tipológicas e metodológicas no trato ao patrimônio, foi somente nos anos 2000 que se assistiu em nível federal o repasse do protagonismo na nominação do bem para as comunidades produtoras do bem ou seus membros. Segundo Ulpiano Bezerra de Meneses, este movimento nunca foi antes pressuposto na legislação brasileira e, desta forma, houve um "deslocamento de matriz" que evidenciou "fissuras na engenharia do saber patrimonial construído sob a ditadura varguista", que centralizou as atividades patrimoniais (MENESES apud MARINS, 2006, p.16-17).

Em Minas Gerais, o registro do Modo de Fazer o Queijo Artesanal da Região do Serro (IEPHA, 2002) abriu caminho para o reconhecimento das vivências e práticas do cotidiano de famílias que vivem da produção artesanal no interior do estado. Sendo o primeiro bem registrado como Patrimônio Cultural Imaterial do estado de Minas Gerais, constitui um importante elemento econômico, simbólico e cultural, que revela 
conhecimentos e práticas das populações que resgatam tradições dos colonizadores portugueses, que levaram o conhecimento à região pelas trilhas do ouro (IEPHA, 2020).

Entretanto, é preciso considerar a configuração geopolítica na seleção do patrimônio imaterial mineiro. A distância temporal entre o registro do modo de fazer o queijo, em 2002, e o reconhecimento das manifestações culturais afro-brasileiras, efetuada com o registro da Festa de Nossa Senhora do Rosário dos Homens Pretos de Chapada do Norte, em 2013, revela a resistência em considerar a presença e importância das populações negras como fundamentais na história e formação de Minas Gerais. Ainda que necessitando de análises mais aprofundadas sobre as políticas de patrimônio em Minas Gerais, esses indícios abrem possibilidades para interpretações que seguem as perspectivas apresentadas por Paulo César Garcez Marins, que faz análises importantes para pensar os processos de exclusão e hierarquização de pessoas durante o tombamento e registro no Brasil nos pós $1980 .^{23}$

\section{Considerações finais}

Partindo do conceito de solidão, este artigo teve como objetivo apresentar possibilidades de análises sobre a temática das políticas públicas voltadas para o patrimônio cultural mineiro com a intenção de identificar elementos de representação sobre Minas Gerais a partir da constatação de discursos de centralização e marginalização de pessoas e lugares na formação da identidade mineira. Tomando como base as representações sobre o sertão mineiro, trouxe reflexões sobre como os processos de seleção de elementos da mineiridade e sua configuração em bens passíveis de tombamento e/ou registro pelo patrimônio também fazem parte de um processo marcado por tensões, conflitos e resistência.

Acredito que, apesar de existir estudos tanto sobre a mineiridade quanto sobre a trajetória das políticas públicas voltadas para o patrimônio cultural, a historiografia mineira ainda carece de pesquisas que promovam este diálogo, mais do que necessário, para a compreensão sobre a seleção e/ou exclusão de elementos identitários. Sendo assim,

\footnotetext{
${ }^{23} \mathrm{Em}$ linhas gerais, os dados relativos às políticas federais evidenciam uma predominância de bens culturais reconhecidos na região Sudeste. Sobre o Nordeste, a região se apresenta como o segundo lugar com maiores indicadores. Existe, portanto, um processo de territorialização de práticas culturais, desconsiderando as suas existências em outros lugares do país. Caso do candomblé, por exemplo. Além disso, mantém-se ainda na concepção patrimonial um olhar muito focado para as referências luso-brasileiras. Quando muito, traz em evidência práticas afro-brasileiras, desconsiderando outros sujeitos constituintes na nossa formação histórica e social, como os indígenas e imigrantes (Marins, 2006).
} 
espero que este artigo seja o ponto de partida para a promoção de uma história regional que problematize a formação dos estereótipos e das identidades, reforçando a luta política contra a exclusão e a favor de uma travessia menos solitária. Caminharemos todos juntos em prol de uma história pública ${ }^{24}$ e que valorize as diferentes trajetórias que passaram e/ou fincaram raízes nesta terra.

\section{Fontes}

Instituto Estadual do Patrimônio Histórico e Artístico de Minas Gerais - IEPHA: INSTITUTO ESTADUAL DO PATRIMÔNIO HISTÓRICO E ARTÍSTICO DE MINAS GERAIS - IEPHA/MG. Dossiê para registro do Artesanato em Barro do Vale do Jequitinhonha: saberes, ofício e expressões artísticas em Minas Gerais. Belo Horizonte, 2018.

INSTITUTO ESTADUAL DO PATRIMÔNIO HISTÓRICO E ARTÍSTICO DE MINAS GERAIS - IEPHA/MG. Guia de bens tombados - 2. ed. - Belo Horizonte: Instituto Estadual do Patrimônio Histórico e Artístico de Minas Gerais, 2014. Disponível em: <http://www.iepha.mg.gov.br/index.php/publicacoes/guia-dos-benstombados $>$. Acesso em: 12/06/2019.

\section{INSTITUTO ESTADUAL DO PATRIMÔNIO HISTÓRICO E ARTÍSTICO DE MINAS GERAIS - IEPHA/MG. Processo de Registro Modo de Fazer o Queijo} Artesanal do Serro. Belo Horizonte, 2002.

\section{Jornais}

ABNER, George; MARTINS, Tadeu; SILBY, Aurélio. Geraes: a realidade do Jequitinhonha. Belo Horizonte: NEOPLAN, 2011. 224p.

O Cruzeiro, em 25 de agosto de 1957.

Biblioteca Digital do Estado de Minas Gerais Raymundo Nonato de Castro: FUNDAÇÃO JOÃO PINHEIRO (FJP). Mapeamento do Artesanato Mineiro. Fundação João Pinheiro. Belo Horizonte: 1979

FUNDAÇÃO JOÃO PINHEIRO (FJP). Plano de Conservação, Valorização e Desenvolvimento de Ouro Preto e Mariana - relatório síntese. Belo Horizonte: Fundação João Pinheiro, Centro de Desenvolvimento Urbano; 1975.

\footnotetext{
${ }^{24}$ Diante de tempos atuais tão difíceis no que diz respeito à construção do conhecimento histórico, sua popularização e os ataques ideológicos que os historiadores têm vivenciado, me apoio em discussões que tentam ampliar a perspectiva da História a partir da história pública e, sob esta perspectiva, realizar análises em torno do patrimônio cultural. Compreendendo as múltiplas facetas em torno do patrimônio e sua relação com a memória, o historiador José Newton Coelho Meneses (2018) trata o patrimônio a partir da experiência compartilhada. Tratando-se da coletividade, as noções sobre o patrimônio ampliaram a representatividade identitária, fugindo da concepção elitista que se tinha até então e que evidenciava a herança europeia. Valoriza-se, com efeito, o patrimônio vivido, como valor de identidade e em transformação (MENESES, 2018, p.72)
} 
FUNDAÇÃO JOÃO PINHEIRO (FJP). CENTRO DE DESENVOLVIMENTO URBANO. Projeto Ouro Preto-Mariana. Proposta técnica e financeira. Belo Horizonte: Fundação João Pinheiro, 1973a.

FUNDAÇÃO JOÃO PINHEIRO (FJP). Terceiro Aniversário. FJP Informações. ANOI I - N. 29 - BELO HORIZONTE, 25 D E agosto D E 1973b.

\section{Legislação}

BRASIL. [Constituição (1934) ]. Constituição da República dos Estados Unidos do Brasil. Rio de Janeiro: Presidência da República, [2019a]. Disponível em:

http://www.planalto.gov.br/ccivil_03/constituicao/constituicao34.htm. Acesso em: 02/05/2019.

BRASIL. [Constituição (1988) ]. Constituição da República Federativa do Brasil. Brasília, DF: Presidência da República, [2019b]). Disponível em:

<http://www.planalto.gov.br/ccivil_03/constituicao/constituicao.htm>. Acesso em: $10 / 06 / 2019$.

BRASIL. Decreto 80.098 de 08 de agosto de 1977. Institui o Programa Nacional de Desenvolvimento do Artesanato e dá outras providências. Disponível em <http://www2.camara.leg.br/legin/fed/decret/1970-1979/decreto-80098-8-agosto-1977429071-publicacaooriginal-1-pe.html>. Acesso em: 08 out. 2018.

BRASIL. Decreto-lei no 25 de 30 de novembro de 1937. Organiza a proteção do patrimônio histórico e artístico nacional. Rio de Janeiro: Presidência da República [2019c]. Disponível em: <http://www.planalto.gov.br/ccivil_03/DecretoLei/Del0025.htm>. Acesso em: 09/05/2019.

MINAS GERAIS. Constituição de 1989. Disponível em: <https://www.almg.gov.br/consulte/legislacao/completa/completa-novamin.html?tipo=Con\&num=1989\&ano=1989>. Acesso em: 01/02/2020.

MINAS GERAIS. Lei 12.040 (1995). Dispõe sobre a distribuição da parcela da receita do produto da arrecadação do ICMS pertencente aos municípios, de que trata o inciso II do parágrafo único do artigo 158 da Constituição Federal e dá outras providências. [2019a]. Disponível em: http://www.fjp.mg.gov.br/robinhood/index.php/leirobinhood/legislacao/lei1204095 .Acesso em: 11/05/2019.

MINAS GERAIS. Lei 18.030 (2009). Disponível em: <htps://www.almg.gov.br/consulte/legislacao/completa/completa-novamin.html?tipo=LEI\&num=18030\&ano=2009> . Acesso em: 01/02/2020.

MINAS GERAIS. Lei 5775, de 30 de setembro de 1971. Autoriza o poder executivo a instituir, sob forma de fundação, o Instituto Estadual do Patrimônio Histórico e Artístico (IEPHA/MG) e dá outras providências. [2019b]. Disponível em:

<https://www.almg.gov.br/consulte/legislacao/completa/completa.html?tipo=LEI\&num

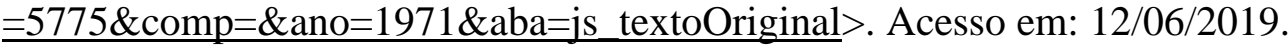


MINAS GERAIS. Executivo. Decreto no 14.194, de 20 de dezembro 1971. Homologa o Regulamento Geral da Comissão do Desenvolvimento do Vale do Jequitinhonha CODEVALE. Minas Gerais, Belo Horizonte, 20 dez. 1971.

\section{Referências}

\section{Páginas de internet}

Biblioteca Digital do Estado de Minas Gerais Raymundo Nonato de Castro. Disponível em: <http://www.bibliotecadigital.mg.gov.br/>. Acesso em: 12/05/2019.

IEPHA. Bens Registrados. Disponível em:http://www.iepha.mg.gov.br/index.php/programas-e-acoes/patrimonio-culturalprotegido/bens-registrados/details/2/4/bens-registrados-modo-de-fazer-o-queijoartesanal-da-regi\%C3\%A3o-do-serro. Acesso em: 01/2020.

Repositório Institucional da Fundação João Pinheiro. Disponível em: <http://www.repositorio.fjp.mg.gov.br/>. Acesso em: 12/05/2019.

Artigos, dissertações, teses e livros

ABREU, Jean Luiz Neves. Nas margens da natureza e da civilização: a viagem de Saint-Hilaire na região do Rio Doce. Estudos de História, Franca, v.12, n.1, p.109-126, jan. 2005.

ABREU, Regina. A emergência do Patrimônio Genético e a nova configuração do campo do Patrimônio. In: ABREU, Regina; CHAGAS, Mário (org.). Memória e patrimônio: ensaios contemporâneos. 2. ed. Rio de Janeiro: Lamparina, 2009.

ALMEIDA, Silvio Luiz de. Racismo estrutural. São Paulo: Sueli Carneiro; Pólen, 2019.

AMADO, Janaína. Região, sertão, nação. Estudos Históricos, Rio de Janeiro, v.8, n.15, 1995, p. 145-151.

ÂNGELO, Marcel Henrique. Vozes das montanhas: a representação social do político mineiro em textos de Aécio Neves. 2005. Dissertação (Mestrado em Teoria Literária e Crítica da Cultura) - Faculdade de Letras, Universidade de São João Del-Rei, São João Del-Rei, 2005.

ANTUNES, Carolina.; FERRAZ, Aderlande Pereira. Dicionário do dialeto rural no Vale do Jequitinhonha - Minas Gerais. Belo Horizonte: Editora UFMG, 2013.

ARAÚJO, Vandel Lopes; MEDEIROS, Bruno Franco. A História de Minas como história do Brasil. Revista do Arquivo Público Mineiro. Vol. 43, fascículo 1, jan/jun, 2007.

BACZKO, Bronislaw. A imaginação social. In: LEACH, Edmund et al. AntroposHomem. Lisboa, Imprensa Nacional/Casa da Moeda, 1985.

BRAGA, Vanuza Moreira. Relíquia e Exemplo, Saudade e Esperança: o SPHAN e a consagração de Ouro Preto. 2010. Dissertação. (Mestrado em História) - Programa de 
Pós-Graduação em História, Política e Bens Culturais. Fundação Getúlio Vargas. 2010. $132 \mathrm{f}$.

CARRARA, Ângelo Alves. Contribuição para a história agrária de Minas Gerais: séculos XVIII e XIX. Mariana: UFOP, departamento de história, 1999.

CARVALHO, José Murilo de. Formação das almas: o imaginário da República no Brasil. São Paulo: Companhia das Letras, 2010.

CARVALHO, José Murilo. Ouro, terra e ferro: vozes de Minas. In: GOMES, Ângela de Castro (org.). Minas e os fundamentos do Brasil moderno. Belo Horizonte: Editora UFMG, 2005, p. 55-78.

CHAGAS, Mario. Memória política e política de memória. In: ABREU, Regina; CHAGAS, Mário (org.). Memória e patrimônio: ensaios contemporâneos. 2. ed. Rio de Janeiro: Lamparina, 2009. p. 136-171.

CHOAY, Françoise. A alegoria do patrimônio. São Paulo: Editora UNESP, 2001

COSTA, João Batista de Almeida. Mineiros e Baianeiros: englobamento, exclusão e resistência. Tese (Doutorado em Antropologia) - Universidade de Brasília. Brasília, 2003. $332 \mathrm{f}$.

CPDOC-FGV. Diretrizes do Estado Novo (1937 - 1945). Serviço do Patrimônio Histórico e Artístico Nacional. Disponível em:

$<$ https://cpdoc.fgv.br/producao/dossies/AEraVargas1/anos37-

45/EducacaoCulturaPropaganda/SPHAN>. Acesso em: 10/06/2019.

FARIA, Maria Auxiliadora. (1992). "A política da Gleba": As classes conservadoras mineiras. Discurso e prática na primeira República. Tese (Doutorado em História Social) - Universidade de São Paulo, São Paulo.

FERREIRA, Loyane Aline Pessato. A soma de luzes na construção da felicidade pública e a reflexão sobre o passado português: política e história na Revista do IHGB (1838-1889). 2010. Dissertação (Mestrado em História) - Universidade Estadual de Campinas, Campinas.

GONÇALVES, José Reginaldo Santos. O Patrimônio como categoria de pensamento. In: ABREU, Regina; CHAGAS, Mário (org.). Memória e patrimônio: ensaios contemporâneos. 2. ed. Rio de Janeiro: Lamparina, 2009. p. 25-33.

HARTOG, François. Tempo e Patrimônio. Varia História, Belo Horizonte, vol. 22, n. 36, p.261- 273, jul.-dez, 2006.

HORTA, Cid Rabelo. Famílias governamentais de Minas Gerais. [1956]. Análise \& Conjuntura, Belo Horizonte, 1 (2). p. 111-142, mai/ago, 1986.

JULIÃO, Letícia. Belo Horizonte: Itinerários da cidade moderna (1891-1920). 1992. Dissertação (Mestrado em História). Faculdade de Filosofia e Ciências Humanas. Universidade Federal de Minas Gerais, Belo Horizonte. 
KRENAK, Ailton. Ideias para adiar o fim do mundo. São Paulo: Companhia das Letras, 2019.

LIMA, Nísia Verônica Trindade. Um sertão chamado Brasil: intelectuais e representação geográfica da identidade nacional. 2. ed., aumentada. São Paulo: HUCITEC, 2013.

MAGALHÃES, Aline Montenegro. Verbere. Inspetoria de Monumentos Nacionais (1934-1937). IPHAN. Dicionário do Patrimônio Cultura. Disponível em: $<$ http://portal.iphan.gov.br/dicionarioPatrimonioCultural/detalhes/29/inspetoria-demonumentos-nacionais-1934-1937>. Acesso em: 12/05/2019.

MARINS, Paulo César Garcez. Novos patrimônios, um novo Brasil? Um balanço das políticas patrimoniais federais após a década de 1980. Estudos Históricos, Rio de Janeiro, vol. 29, n. 57, 2016, p.09-28.

MARQUEZ, Gabriel Garcia. A solidão da América Latina. RevIU. Vol. 2, Num. 1, p. 12-14, 2014. Disponível em: https://revistas.unila.edu.br/IMEA-

UNILA/article/view/249/246. Acesso em: 30/12/2019.

MARQUEZ, Gabriel Garcia; ZAGURY, Eliane. Cem anos de solidão. 2. ed. Rio de Janeiro: Sabiá, 1969.

MARTINS, Tadeu. Geraes: uma história do Jequitinhonha, 2012.

MENESES, José Newton Coelho. Todo Patrimônio é uma forma de história pública? In: BORGES, Viviane Trindade; MAUAD, Ana Maria; SANTHIAGO, Ricardo (Org.). Que história pública queremos? What public history do we want? São Paulo: Letra e Voz, 2018.

MITRE, Antonio. História: memória e esquecimento. O Dilema do Centauro: ensaios de teoria da história e pensamento latino-americano. Belo Horizonte: Editora UFMG, 2003, p.11-28.

MORAES, Nilson Alves; SOUZA, Luciana Christina Cruz e. Estado e Patrimônio: o IEPHA/MG e o caso de Minas Gerais. IV SEMINÁRIO INTERNACIONAL POLÍTICAS CULTURAIS. 16 a 18 de outubro/2013. Setor de Políticas Culturais Fundação Casa de Rui Barbosa, Rio de Janeiro.

PAULA, João Antônio de. Raízes da modernidade em Minas Gerais. Belo Horizonte: Autêntica Editora, 2000.

RAMALHO, Juliana Pereira. Modelando a vida e entalhando a arte: 0 artesanato do Vale do Jequitinhonha. Dissertação (Mestrado em Extensão Rural) - Universidade Federal de Viçosa, Viçosa, 2010.

RAMALHO, Walderez Simões Costa. A Historiografia da mineiridade: Trajetórias e significados na história republicana do Brasil. 2015 Dissertação (Mestrado em História) - Universidade Federal de Minas Gerais, Faculdade de Filosofia e Ciências Humanas. $170 f$. 
RANGEL, Márcio F. "Políticas públicas e museus no Brasil”. In: Marcus Granato, Cláudia Penha dos Santos e Maria Lucia de Niemeyer Matheus Loureiro. (org.). MAST Colloquia - O Caráter Político dos Museus. Rio de Janeiro: MCT, MAST, v. 12, p. 119-135, 2010.

REIS, José Carlos. O “descobrimento do Brasil”. Anos 1850: Varnhagen. As identidades do Brasil 1: de Varnhagen a FHC. Rio de Janeiro: FGV, 2007. $9^{\circ}$ ed.

REIS, Liana Maria. Mineiridade: identidade regional e ideologia. Cadernos de História, Belo Horizonte, v. 9, n. 11, p. 89-97, jan./jun. 2007.

SANTOS, Antônio Bispo do. Colonização, Quilombos: modos e significados. Brasília, s.n, 2015.

SANTOS, Boaventura de Sousa. Para além do pensamento abissal: das linhas globais a uma ecologia dos saberes. In: STARLING, Heloisa M. M.; ALMEIDA, Sandra R. G. (org.). Sentimentos do Mundo: ciclo de conferências dos 80 anos da UFMG. Belo Horizonte: d. UFMG, 2009, p.77-128

SERVILHA, Matheus de Moraes. Vale do Jequitinhonha: a emergência de uma região. In: NOGUEIRA, Maria das Dores Pimentel [org.]. Vale do Jequitinhonha: Cultura e desenvolvimento. Belo Horizonte: UFMG/PROEX, 2012.

SOUZA, Candice Vidal e. A pátria geográfica: sertão e litoral no pensamento social brasileiro. Goiânia: UFG, 1997.

SOUZA, José Moreira de; Associação Nacional de Pós-graduação e Pesquisa em Ciências Sociais. Cidade: momentos e processos: Serro e Diamantina na formação do norte mineiro no século XIX. São Paulo: Marco Zero, 1993.

TODOROV, Tzvetan. A descoberta da América. A conquista da América: a questão do outro. Tradução Beatriz Perrone-Moisés. 3.ed. São Paulo: Martins Fontes, 2003.

VIEIRA, Daniela Guimarães. A vida nunca tá ruim, a vida sempre taboa: 0 artesanato do Vale do Jequitinhonha e a antropologia na perspectiva da extensão universitária. 2010. 232 f. Dissertação (mestrado). Programa de Pós-Graduação em Antropologia, Universidade Federal de Minas Gerais, Belo Horizonte, 2010.

VILLALTA, Luiz Carlos. (org.). História de Minas Gerais: as Minas setecentistas. v.1. Belo Horizonte: Autêntica; Companhia do Tempo, 2007a.

VILlALTA, Luiz Carlos. (org.). História de Minas Gerais: as Minas setecentistas. v.2. Belo Horizonte: Autêntica; Companhia do Tempo, 2007b. 